\title{
PREDICTABLE OXYGEN CONCENTRATIONS WITH THE BIRD RESPIRATOR*
}

\author{
C. H. N. Macdonald, M.D. $†$
}

IN 1964, Fairley and Britt investigated the adequacy of the air-mix control of ventilators operated from an oxygen source. ${ }^{1}$ The mean inspired oxygen percentages were measured at various cycling pressures, and with the Bird Mark 7 ventilator the oxygen levels varied from 51.5 to 96.8 per cent, being highest at low flows and at high cycling pressures. Consequently, these authors recommended that this type of equipment be driven by compressed air, the oxygen being added as required.

Harrison $^{2}$ showed that as the pressure in the right-hand chamber of the ventilator increased, the flow through the venturi fell; therefore, as inflation proceeded, the amount of air entrained was reduced and the concentration of oxygen increased. The lower the flow setting, and hence the flow through the injector, the greater the percentage contribution of the nebulizer oxygen to the inspired mixture.

In following up this problem, Sellery and Fairley published in 1967 a study of the inspired oxygen concentrations delivered by the Bird ventilator when operated from a compressed air source with oxygen added to the ambient or to the pressurized side of the ventilator. ${ }^{3}$ They found that when oxygen was added to the ambient side of the ventilator at any given oxygen flow rate, the inspired oxygen concentrations decreased as the cycling pressure was increased (Fig. 1). When the oxygen was added to the pressurized side, high oxygen concentrations were delivered at low cycling pressures (Fig. 2), and this was thought to be due to the added oxygen accounting for a high proportion of the inspired volume when cycling occurred quickly. The inspired oxygen concentrations were seen to rise to a high level again at the high cycling pressures due to a decrease in the amount of air entrainment. In both instances little change was produced in the inspired oxygen concentration by changes in the flow rate within the clinically used range.

In view of the above findings, it was thought advisable to investigate the adequacy of the Bird Parallel Inspiratory Flow Mixing Cartridge, as regards its ability to supply a constant predictable level of oxygen in the inspired gas mixture. This cartridge may be installed in the line of the primary pneumatic power source driving the Bird respirator, and is said by the manufacturer to furnish the following:

(1) Oxygen-air dilution during the inspiratory phase for specific oxygen concentrations; e.g. the primary gas for low to moderate oxygen concentrations would be compressed air. Oxygen would be delivered into the inspiratory breathing circuit through

'Presented at the Annual Meeting, Canadian Anaesthetists' Society, May 13-16, 1968.

tDepartment of Anaesthesia, University of Western Ontario, London, Canada.

Can. Anaes. Soc. J., vol. 15, no. 6, November 1968 
the Bird 500 c.c. micronebulizer jet or accessory port ... Phasic inspiratory oxygen flows are manually selected by adjustment of the secondary oxygen metering valve....

(2) A specific mixture of any two respiratory or anaesthetic gases during the mechanical ventilation of the lung.4

This would seem to indicate that the manufacturer expects this apparatus to provide us with a means of supplying to the patient an easily predictable mixture of gases so that we are able to deliver a predictable oxygen concentration by merely turning a dial. It was the purpose of this study to determine if such is the case.

The Bird parallel inspiratory flow mixing cartridge (999 1289) is composed of three sections (Fig. 3). The gold section on the left is interposed in the line of the primary gas powering the respirator, the toggle switch being an on-off switch for the primary power source. This section of the cartridge is connected to the 500 c.c. micronebulizer by a small-bore pressure line. The green section on the right is connected to an oxygen source under pressure and is also connected to the micronebulizer, the nebulizer becoming a mixing chamber. This section is primarily an oxygen metering valve. Between these two is a connecting portion, which is joined to the small-bore pressure line from the respirator to the expiratory valve and is involved in the triggering of the cartridge in conjunction with the respirator. There is a flow of air and oxygen through the cartridge into the nebulizer only during the inspiratory phase. Consequently, there is no flow of oxygen into the circuit during the expiratory phase, thus eliminating one of the causes of the faulty oxygen concentrations as shown by Harrison.

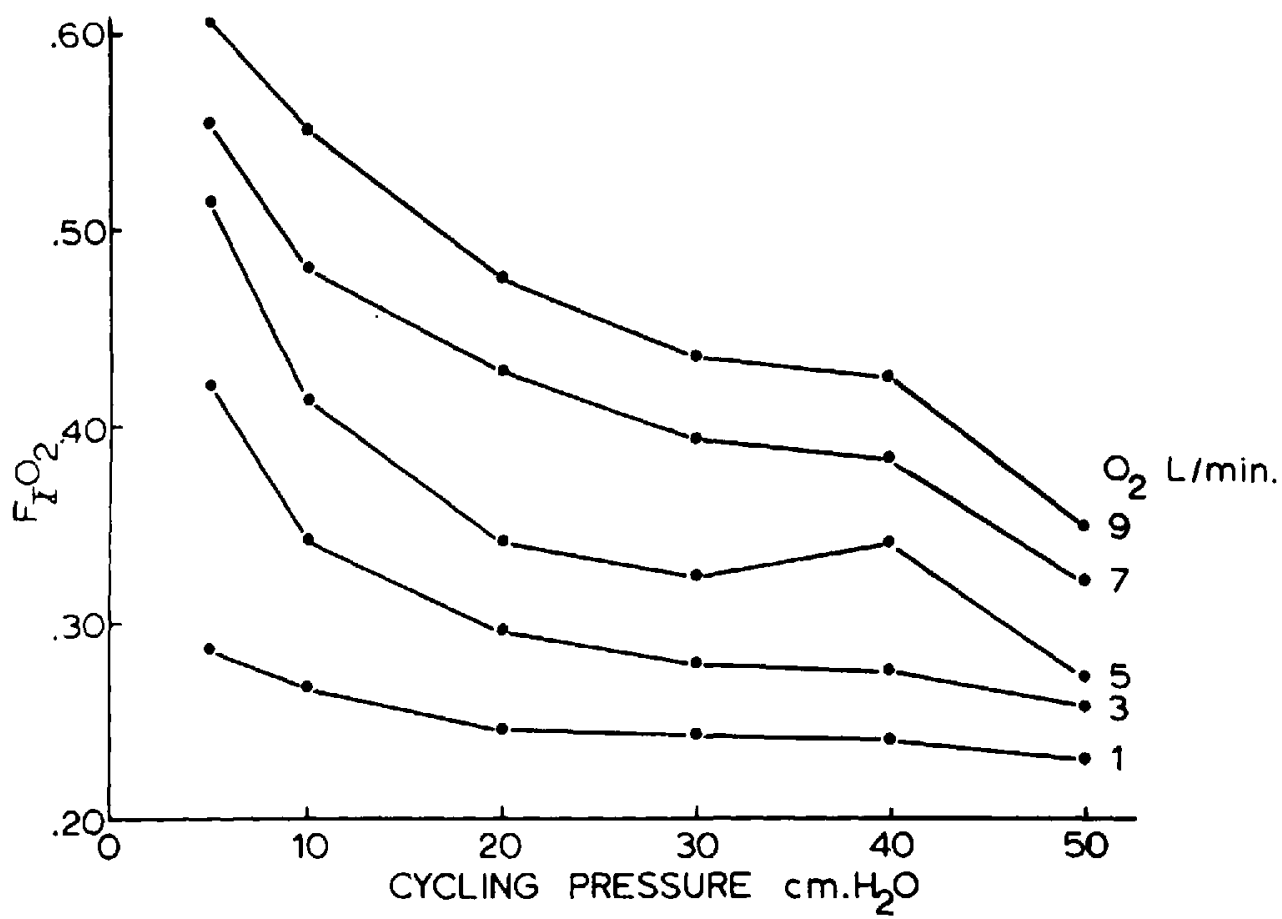

Figune 1. $\mathrm{F}_{\mathrm{I}_{2}}$ values for oxygen added to ambient side of respirator. Peak flow rate 60 L./min. (From Sellery \& Fairley.) 


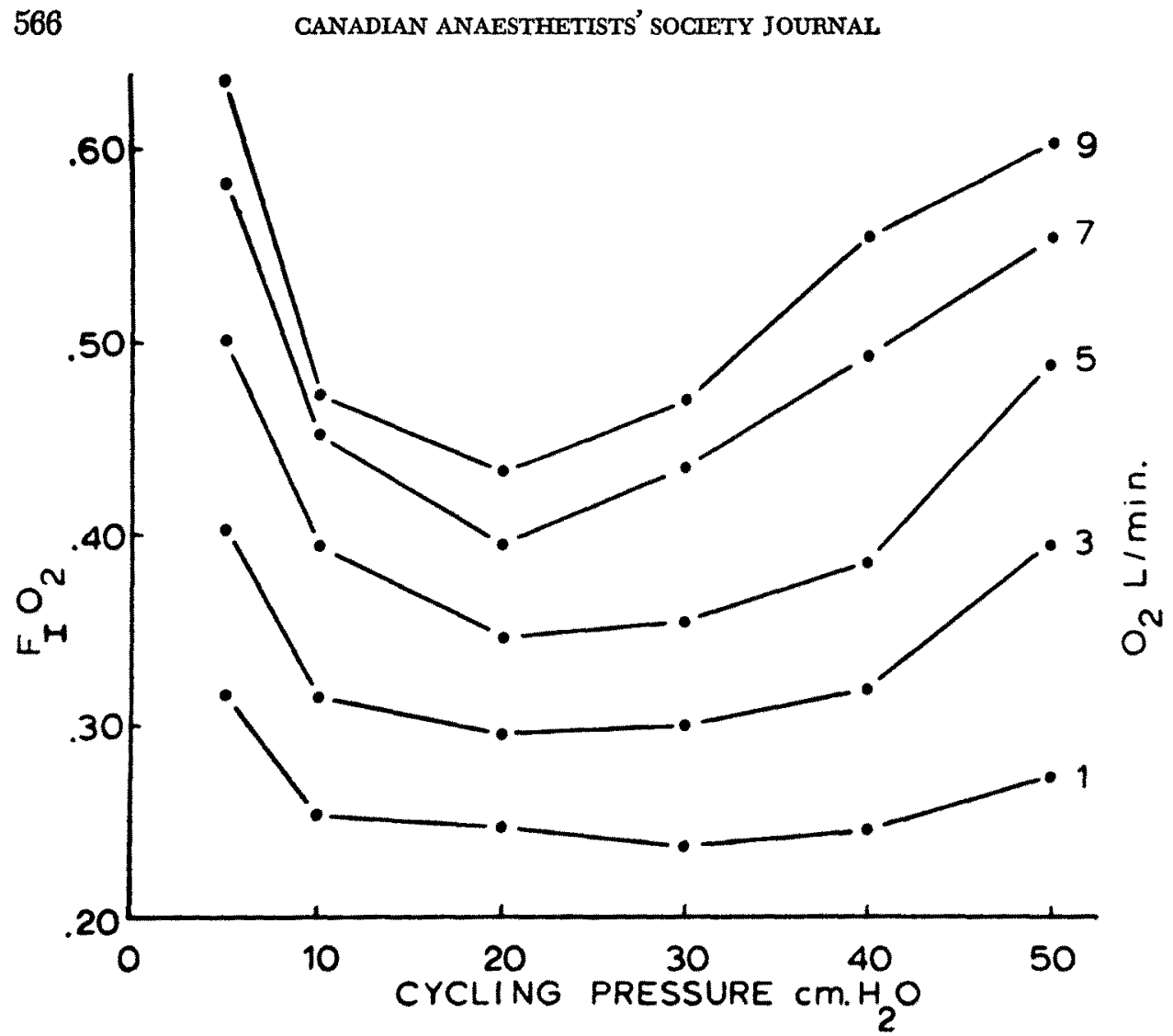

Frgure 2. $F_{I_{0_{2}}}$ values for oxygen added to pressurized side of respirator. Peak flow rate 60 L./min. (From Sellery \& Fairley.)

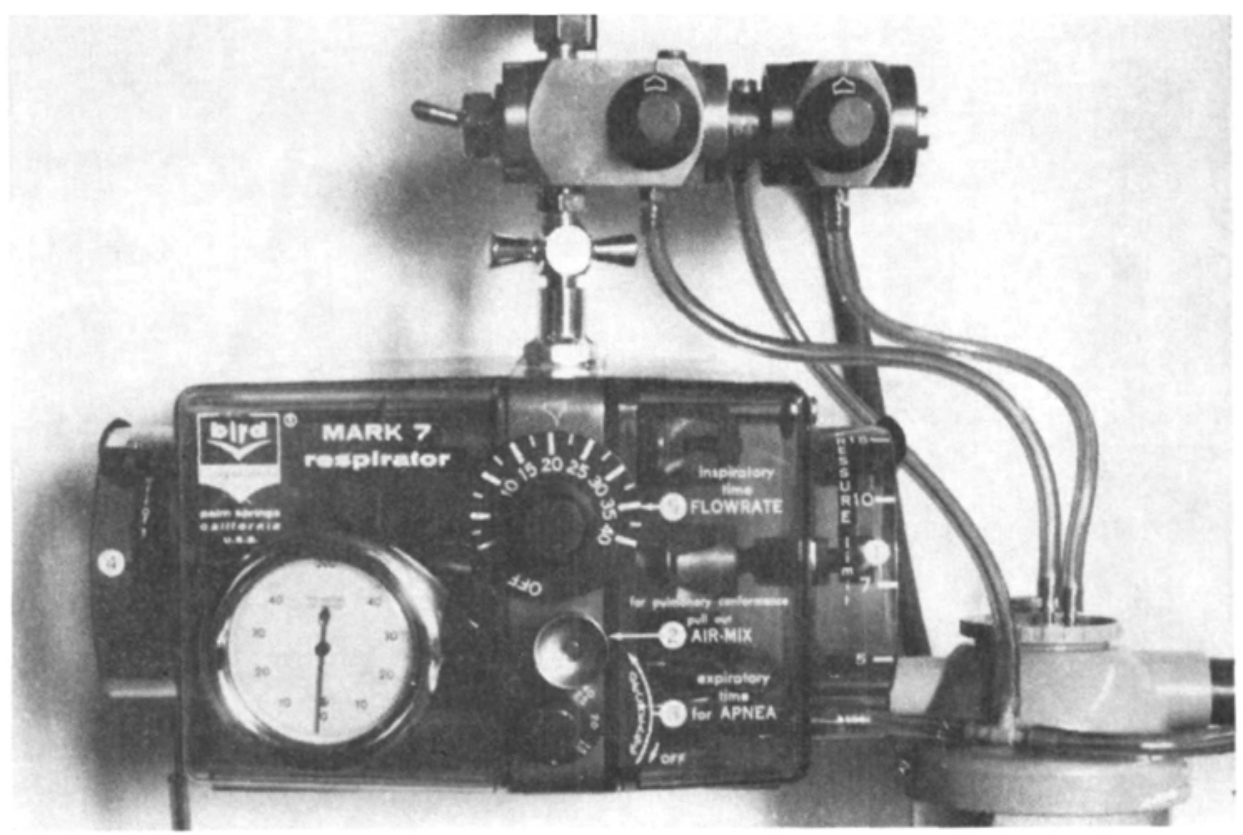

Figure 3 


\section{METHOD}

A Bird Mark 7 respirator was used during the investigation. As shown in Figure 4, the cartridge was connected to the compressed air and oxygen sources as described above. A $60 \mathrm{~L}$. metal drum was used as a lung analogue and was ventilated using a $9.5 \mathrm{~mm}$. endotracheal tube., The exhalation port of the expiratory valve was connected by corrugated rubber tubing to a Wright respirometer and this in turn to a three-way valve leading into a Douglas bag. Between these last two was a sampling port for the removal of samples of "expired gas" for measurement of the oxygen tension. These measurements were made using an Instrumentation Laboratories $\mathrm{Po}_{2}$ electrode and the results were converted into oxygen concentration using the formula

$$
\mathrm{FIo}_{2}=\mathrm{Po}_{2} /(\mathrm{BP}-\mathrm{VP})
$$

where $\mathrm{FIo}_{2}$ is the fraction of the inspired air which is oxygen, $\mathrm{BP}$ is the barometric pressure, and VP is the vapour pressure.

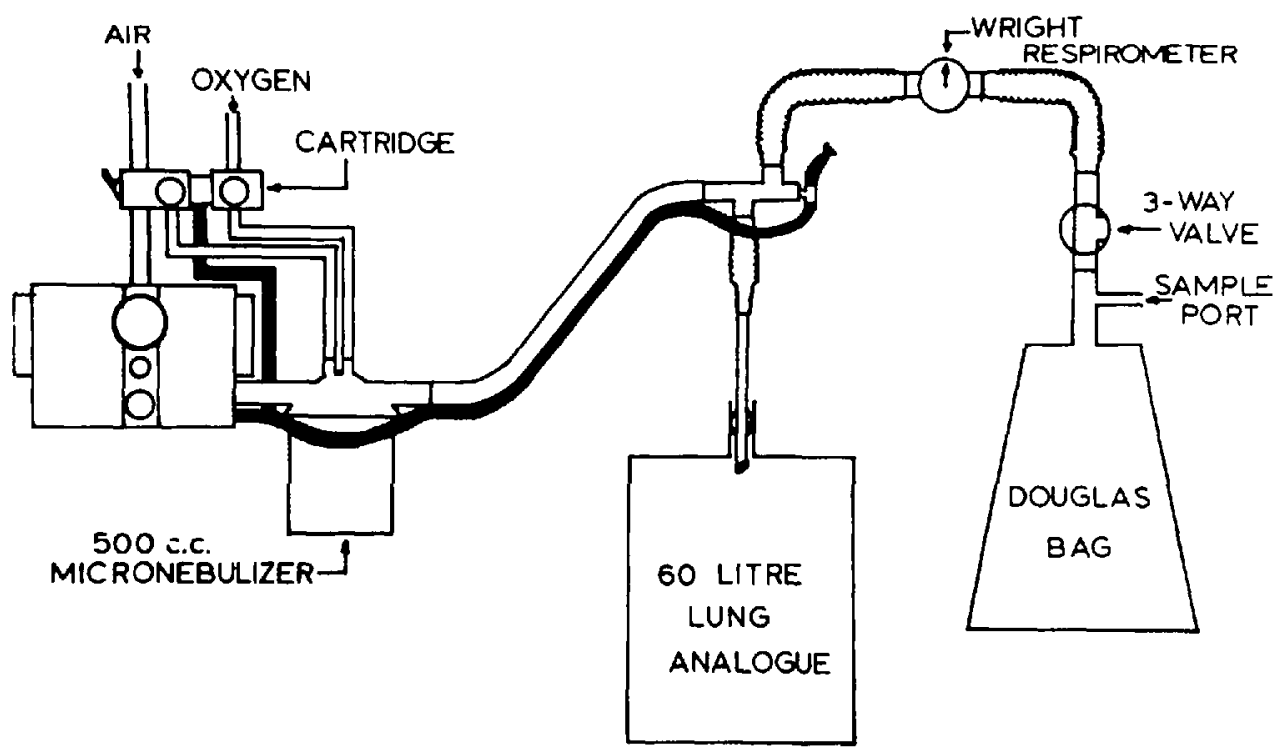

Figure 4. System for evaluation of parallel inspiratory flow mixing cartridge.

The parallel inspiratory flow mixing cartridge has two adjustment knobs, one on the left which controls the flow of the primary gas (air) to the nebulizer, and the other on the right which controls the flow of oxygen. Neither of these controls is calibrated by the manufacturer, so for this experimental work a sheet of plastic was inserted behind them and marked in eighths of a full turn for each one (Fig. 5).

It was felt that we should first know how much the flow through the respirator would be increased by the use of the mixing cartridge. Consequently the flow 


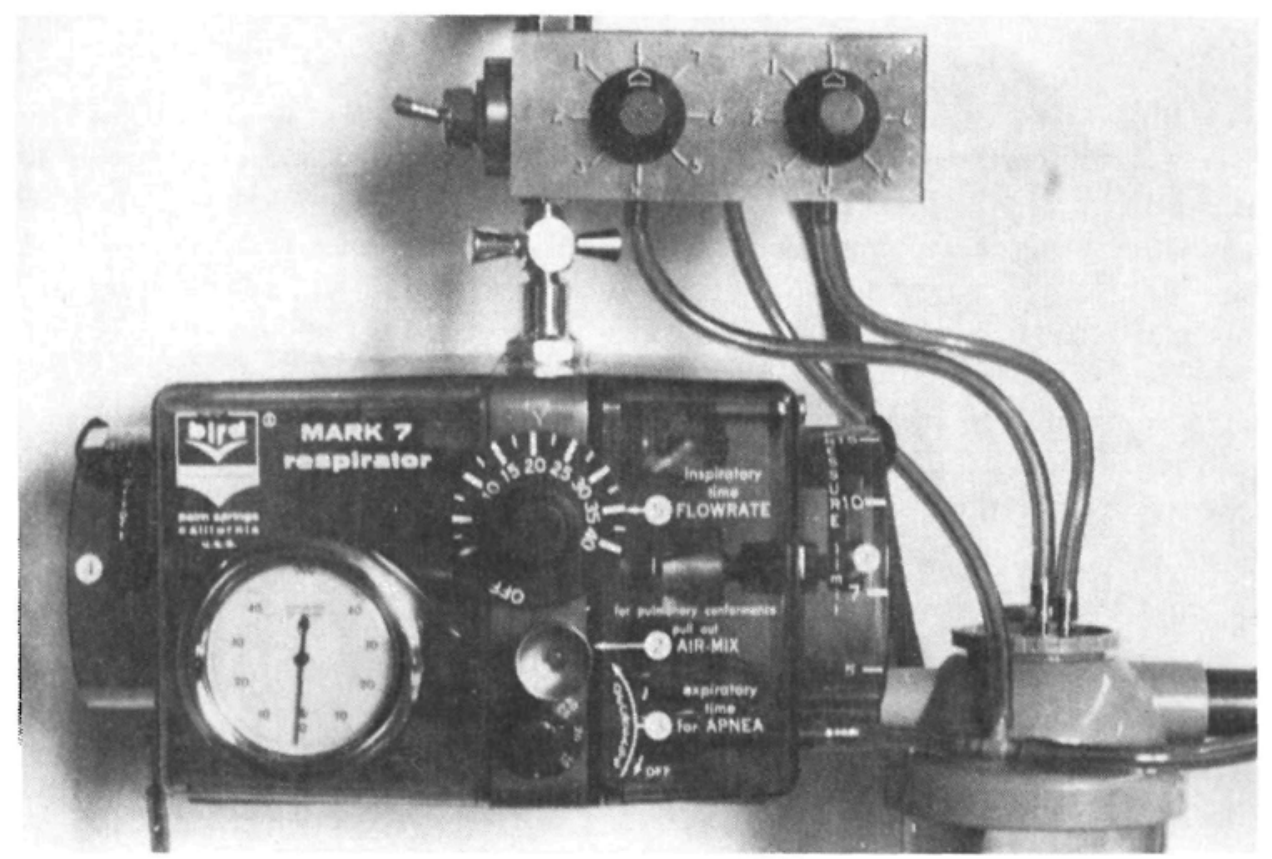

Figure 5

through the respirator against no resistance was measured in litres per minute under the following conditions:

1. just the respirator driven by compressed air;

2. the respirator driven by compressed air plus the nebulizer cartridge on one full turn;

3. the respirator driven by compressed air plus the oxygen cartridge on one full turn;

4. the respirator driven by compressed air plus the nebulizer and the oxygen cartridges both on one full turn.

The results of these measurements are shown in Table I. Measurements of the oxygen tension of the "expired air" were made under the following conditions:

1. various settings of flow rate and pressure (the actual flow and actual pressure in the lung analogue were not measured) and settings of the oxygen cartridge from 1 to 8 with the air or nebulizer cartridge on one full turn and the air-mix control pulled out;

2. constant pressure and flow rate settings at 15 , nebulizer cartridge on only one-half turn, and the oxygen cartridge turned through all settings from 1 to 8 ;

3. constant flow rate and pressure settings, both at 15 , the nebulizer cartridge turned off, and the oxygen cartridge used as the source of nebulizing gas through all of its eight settings;

4. constant minute volume, variable flow rate and pressure settings, air-mix control pushed in, nebulizer cartridge on one full turn, and the oxygen cartridge at settings 7 and 8 ;

5. constant measured pressure in the lung analogue, variable flow rate settings, 
TABLE I

Changes in Flow Brought About by the Additional Volume through the Nebulizer and Oxygen Flow Cartridges

\begin{tabular}{rcccc}
\hline \hline $\begin{array}{c}\text { Flow rate } \\
\text { setting }\end{array}$ & Resp. air only & $\begin{array}{c}\text { Resp. air plus } \\
\text { neb. } 1 \text { f.t. }\end{array}$ & $\begin{array}{c}\text { Resp. air plus } \\
\text { O }_{2} \text { 1 f.t. }\end{array}$ & $\begin{array}{c}\text { Resp. air plus } \\
\text { both 1 f.t. }\end{array}$ \\
\hline 5 & 45.500 & 51.000 & 58.810 & 59.960 \\
10 & 72.420 & 78.660 & 83.000 & 88.790 \\
15 & 81.490 & 83.630 & 88.410 & 95.770 \\
20 & 85.560 & 91.360 & 91.050 & 91.280 \\
25 & 86.380 & 91.250 & 93.490 & 100.810 \\
30 & 87.230 & 91.420 & 93.970 & 101.500 \\
35 & 87.430 & 90.860 & 94.360 & 101.220 \\
\hline
\end{tabular}

TABLE II

$\mathrm{FI}_{\mathrm{O}_{2}}$ Values and Means

\begin{tabular}{|c|c|c|c|c|c|c|c|c|c|}
\hline FR & $\mathrm{P}$ & 1 & 2 & 3 & 4 & 5 & 6 & 7 & 8 \\
\hline $\begin{array}{l}10 \\
10 \\
10 \\
10\end{array}$ & $\begin{array}{l}10 \\
10 \\
10 \\
10\end{array}$ & $\begin{array}{l}.276 \\
.312 \\
.276 \\
.269\end{array}$ & $\begin{array}{l}.305 \\
.319 \\
.313 \\
.305\end{array}$ & $\begin{array}{l}.363 \\
.363 \\
.378 \\
.363\end{array}$ & $\begin{array}{l}.422 \\
.422 \\
.422 \\
.432\end{array}$ & $\begin{array}{l}.472 \\
.465 \\
.472 \\
.465\end{array}$ & $\begin{array}{l}.523 \\
.523 \\
.538 \\
.502\end{array}$ & $\begin{array}{l}.574 \\
.577 \\
.574 \\
.538\end{array}$ & $\begin{array}{l}.625 \\
.618 \\
.603 \\
.574\end{array}$ \\
\hline $\begin{array}{l}10 \\
10 \\
10 \\
10\end{array}$ & $\begin{array}{l}20 \\
20 \\
20 \\
20\end{array}$ & $\begin{array}{l}.283 \\
.261 \\
.283 \\
.283\end{array}$ & $\begin{array}{l}.301 \\
.304 \\
.304 \\
.304\end{array}$ & $\begin{array}{l}.342 \\
.341 \\
.341 \\
.334\end{array}$ & $\begin{array}{l}.374 \\
.377 \\
.377 \\
.392\end{array}$ & $\begin{array}{l}.400 \\
.424 \\
.428 \\
.428\end{array}$ & $\begin{array}{l}.429 \\
.464 \\
.443 \\
.464\end{array}$ & $\begin{array}{l}.458 \\
.515 \\
.501 \\
.508\end{array}$ & $\begin{array}{l}.523 \\
.537 \\
.537 \\
.537\end{array}$ \\
\hline $\begin{array}{l}15 \\
15 \\
15 \\
15\end{array}$ & $\begin{array}{l}15 \\
15 \\
15 \\
15\end{array}$ & $\begin{array}{l}.232 \\
.233 \\
.265 \\
.238\end{array}$ & $\begin{array}{l}.274 \\
.280 \\
.279 \\
.280\end{array}$ & $\begin{array}{l}.361 \\
.323 \\
.329 \\
.330\end{array}$ & $\begin{array}{l}.332 \\
.352 \\
.379 \\
.366\end{array}$ & $\begin{array}{l}.412 \\
.402 \\
.401 \\
.402\end{array}$ & $\begin{array}{r}.460 \\
.425 \\
.458 \\
.438\end{array}$ & $\begin{array}{l}.494 \\
.401 \\
.501 \\
.480\end{array}$ & $\begin{array}{l}.517 \\
.501 \\
.522 \\
.517\end{array}$ \\
\hline $\begin{array}{l}15 \\
15 \\
15 \\
15\end{array}$ & $\begin{array}{l}20 \\
20 \\
20 \\
20\end{array}$ & $\begin{array}{l}.239 \\
.242 \\
.260 \\
.246\end{array}$ & $\begin{array}{l}.268 \\
.279 \\
.282 \\
.289\end{array}$ & $\begin{array}{l}.298 \\
.293 \\
.321 \\
.326\end{array}$ & $\begin{array}{l}.344 \\
.341 \\
.355 \\
.347\end{array}$ & $\begin{array}{l}.377 \\
.363 \\
.391 \\
.384\end{array}$ & $\begin{array}{l}.431 \\
.377 \\
.427 \\
.405\end{array}$ & $\begin{array}{l}.446 \\
.409 \\
.466 \\
.441\end{array}$ & $\begin{array}{r}.487 \\
.472 \\
.521 \\
.488\end{array}$ \\
\hline $\begin{array}{l}20 \\
20 \\
20 \\
20\end{array}$ & $\begin{array}{l}15 \\
15 \\
15 \\
15\end{array}$ & $\begin{array}{l}.243 \\
.233 \\
.259 \\
.255\end{array}$ & $\begin{array}{l}.291 \\
.283 \\
.288 \\
.288\end{array}$ & $\begin{array}{l}.329 \\
.328 \\
.334 \\
.324\end{array}$ & $\begin{array}{l}.385 \\
.374 \\
.374 \\
.374\end{array}$ & $\begin{array}{l}.378 \\
.363 \\
.403 \\
.403\end{array}$ & $\begin{array}{l}.422 \\
.414 \\
.435 \\
.432\end{array}$ & $\begin{array}{l}.446 \\
.449 \\
.456 \\
.460\end{array}$ & $\begin{array}{l}.468 \\
.485 \\
.70 \\
.482\end{array}$ \\
\hline $\begin{array}{l}20 \\
20 \\
20 \\
20\end{array}$ & $\begin{array}{l}20 \\
20 \\
20 \\
20\end{array}$ & $\begin{array}{l}.253 \\
.245 \\
.242 \\
.239\end{array}$ & $\begin{array}{l}.284 \\
.267 \\
.285 \\
.264\end{array}$ & $\begin{array}{l}.310 \\
.303 \\
.326 \\
.312\end{array}$ & $\begin{array}{l}.346 \\
.342 \\
.333 \\
.341\end{array}$ & $\begin{array}{l}.375 \\
.375 \\
.369 \\
.365\end{array}$ & $\begin{array}{l}.389 \\
.397 \\
.399 \\
.402\end{array}$ & $\begin{array}{l}.433 \\
.426 \\
.428 \\
.416\end{array}$ & $\begin{array}{l}.447 \\
.447 \\
.449 \\
.435\end{array}$ \\
\hline $\begin{array}{l}20 \\
20 \\
20 \\
20\end{array}$ & $\begin{array}{l}30 \\
30 \\
30 \\
30\end{array}$ & $\begin{array}{l}.230 \\
.236 \\
.241 \\
.241\end{array}$ & $\begin{array}{l}.285 \\
.277 \\
.277 \\
.277\end{array}$ & $\begin{array}{l}.328 \\
.314 \\
.321 \\
.314\end{array}$ & $\begin{array}{l}.382 \\
.350 \\
.365 \\
.343\end{array}$ & $\begin{array}{l}.409 \\
.387 \\
.394 \\
.380\end{array}$ & $\begin{array}{l}.426 \\
.416 \\
.423 \\
.416\end{array}$ & $\begin{array}{l}.453 \\
.453 \\
.438 \\
.453\end{array}$ & $\begin{array}{r}.482 \\
.482 \\
.482 \\
.482\end{array}$ \\
\hline $\begin{array}{l}30 \\
30 \\
30 \\
30\end{array}$ & $\begin{array}{l}20 \\
20 \\
20 \\
20\end{array}$ & $\begin{array}{l}.289 \\
.282 \\
.282 \\
.279\end{array}$ & $\begin{array}{l}.304 \\
.297 \\
.297 \\
.313\end{array}$ & $\begin{array}{l}.333 \\
.318 \\
.333 \\
.342\end{array}$ & $\begin{array}{l}.362 \\
.369 \\
.369 \\
.385\end{array}$ & $\begin{array}{l}.384 \\
.398 \\
.405 \\
.400\end{array}$ & $\begin{array}{l}.427 \\
.434 \\
.441 \\
.443\end{array}$ & $\begin{array}{l}.485 \\
.485 \\
.475 \\
.494\end{array}$ & $\begin{array}{l}.543 \\
.528 \\
.528 \\
.538\end{array}$ \\
\hline $\begin{array}{l}30 \\
30 \\
30 \\
30\end{array}$ & $\begin{array}{l}30 \\
30 \\
30 \\
30\end{array}$ & $\begin{array}{l}.247 \\
.239 \\
.247 \\
.247\end{array}$ & $\begin{array}{l}.269 \\
.262 \\
.269 \\
.269\end{array}$ & $\begin{array}{l}.298 \\
.283 \\
.298 \\
.301\end{array}$ & $\begin{array}{l}.342 \\
.334 \\
.327 \\
.327\end{array}$ & $\begin{array}{l}.400 \\
.378 \\
.378 \\
.378\end{array}$ & $\begin{array}{l}.414 \\
.400 \\
.400 \\
.422\end{array}$ & $\begin{array}{l}.451 \\
.429 \\
.417 \\
.422\end{array}$ & $\begin{array}{l}.472 \\
.464 \\
.464 \\
.472\end{array}$ \\
\hline Means & & .256 & .287 & .335 & .366 & .401 & .435 & .468 & .505 \\
\hline
\end{tabular}


nebulizer cartridge on one full turn, the air-mix control pulled out, and the oxygen cartridge at settings 7 and 8 ;

6 . the same as number 5 but with the air-mix control pushed in.

During the experiments, pressure tracings were recorded from the lung analogue using a Statham strain gauge transducer and a Schwarzer direct recording instrument.

\section{Results}

The measurements of oxygen tension converted to $\mathrm{F}_{\mathrm{Io}_{2}}$ obtained from the first set of conditions as described above are shown, with the mean values, in Table II. These mean values give a fairly good straight-line relationship (Fig. 6) between the settings of the oxygen cartridge and the percentage of oxygen in the inspired air. The maximum oxygen concentration obtainable was approximately $50-55$ vol. per cent, gradually rising from 21 vol. per cent as the flow through the cartridge was increased.

Oxygen concentrations obtained with the flow rate and pressure settings both at 15 as shown in Tables II and III (conditions 1, 2, and 3) were plotted for changes in the setting of the nebulizer cartridge (Fig. 7). The concentrations obtained with the nebulizer cartridge on one full turn and on only one-half turn did not show any significant difference. However, with the nebulizer cartridge off and the oxygen cartridge as the power source for the nebulizer, there was a

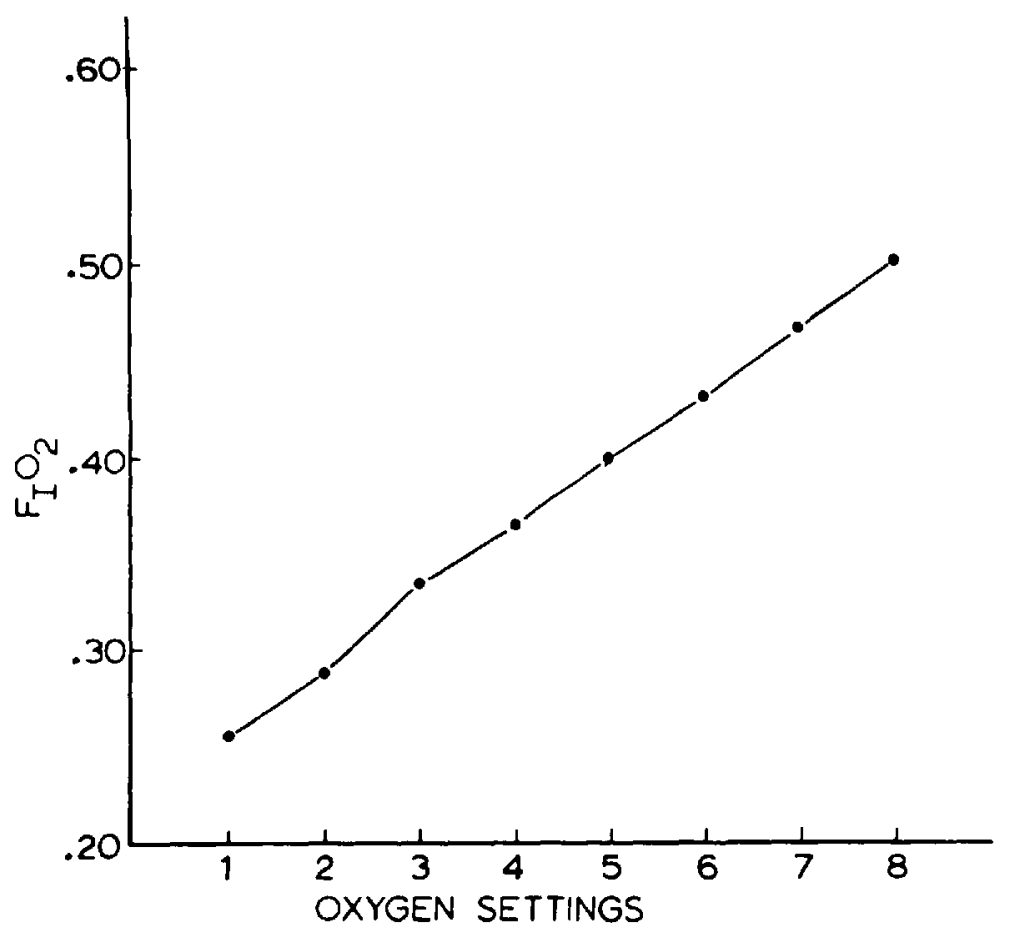

Figure 6. Mean values for $\mathrm{F}_{\mathrm{I}_{\mathrm{O}_{2}}}$ measured at various pressure and flow rate settings described in Table II with nebulizer cartridge on one full turn and air-mix control pulled out. 
TABLE III

Values for $\mathrm{Fi}_{\mathrm{O}_{2}}$ with Constant Minute Volume, Pressure Setting 15, Flow Rate Setting 15, and the Nebulizer Cartridge On One-half Turn Only and Off Completely with the OXygen as The Power Source for the Nebulizer

\begin{tabular}{lcccccccc}
\hline \hline $\mathrm{O}_{2}$ cart. setting & 1 & 2 & 3 & 4 & 5 & 6 & 7 & 8 \\
\hline Nebulizer one-half turn & .230 & .280 & .326 & .357 & .407 & .464 & .503 & .555 \\
Nebulizer off & .238 & .381 & .529 & .635 & .734 & .767 & .820 & .873 \\
\hline
\end{tabular}

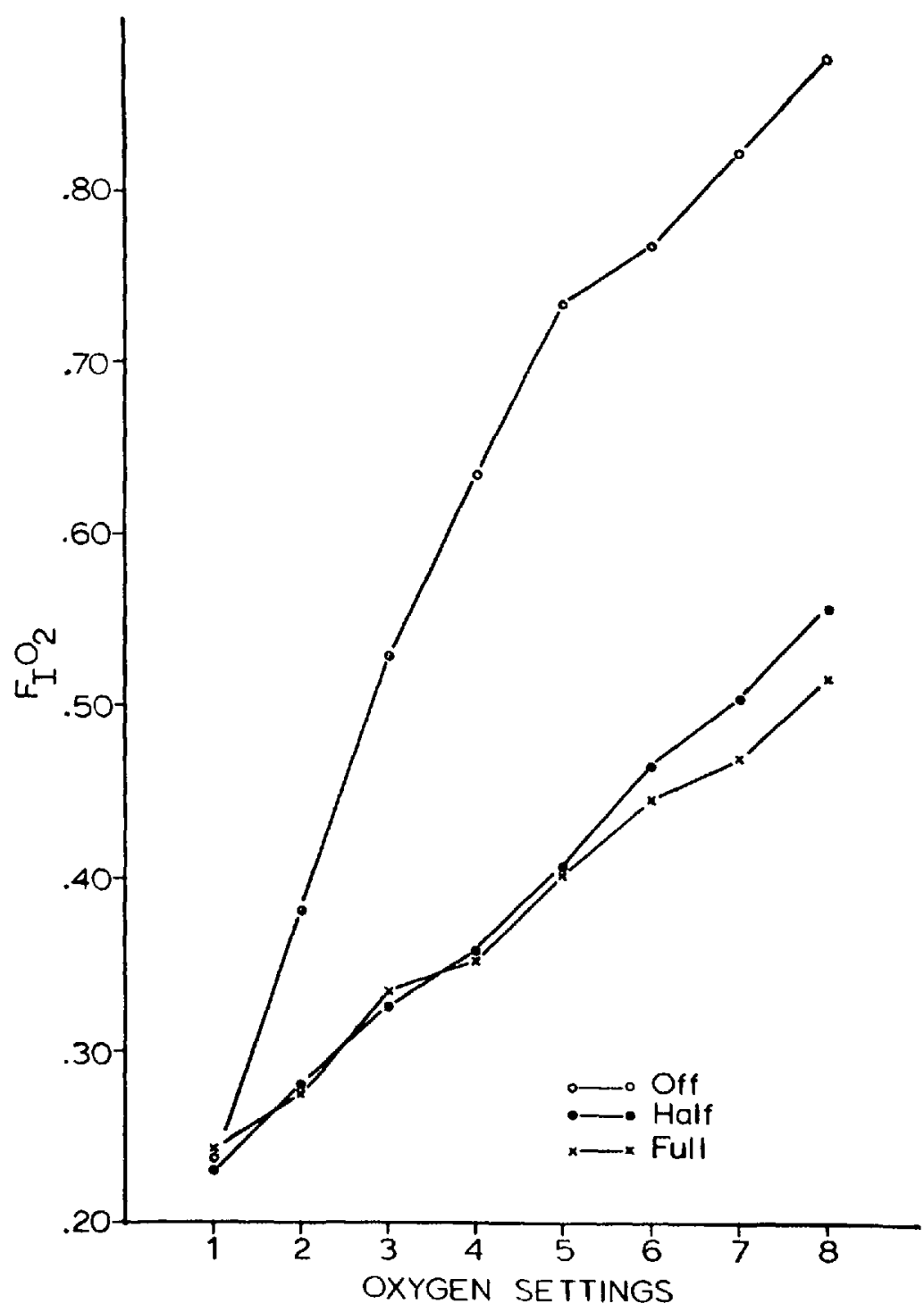

Figure 7. Effect on oxygen concentration of varying the flow through the nebulizer cartridge. 
marked increase, up to 87 vol. per cent, in the oxygen concentration as the flow through the cartridge was increased. Since these levels are above the clinically desirable range in the large majority of cases, this arrangement should probably not be used. Moreover, with the nebulizing flow dial set below one-half turn, the flow of mist from the nebulizer was judged inadequate.

Since there was no appreciable difference in the oxygen concentrations obtained with variations in flow through the nebulizer portion of the cartridge above one-half, the remainder of the experimental work was carried out with the nebulizer cartridge set at one full turn.

With a constant flow rate setting of 20 the oxygen concentration (from Table II) was fairly stable with variation in the cycling pressure setting, except for a slight depression in the middle range of pressure settings (Fig, 8). These findings are similar to those of Sellery and Fairley where the oxygen was added to the pressurized side of the respirator, except that in their case the flow of oxygen into the circuit continued during expiration and was not an interrupted flow as with the cartridge. They believed that the rise in oxygen concentration at the higher cycling pressures was due to falling air entrainment.

This depression in the middle range of pressure settings was still present (Fig. 9) when the same experiment was performed with the air-mix control pushed in (condition 4). Consequently, this variation, which was of such a degree as to be clinically insignificant and did not appreciably interfere with the predictability of the oxygen concentrations, was thought to be due to an inherent characteristic of the Bird valve.

The oxygen concentrations (from Table II) obtained when the cycling pressure setting was kept constant and the flow rate varied (Fig. 10) again showed low

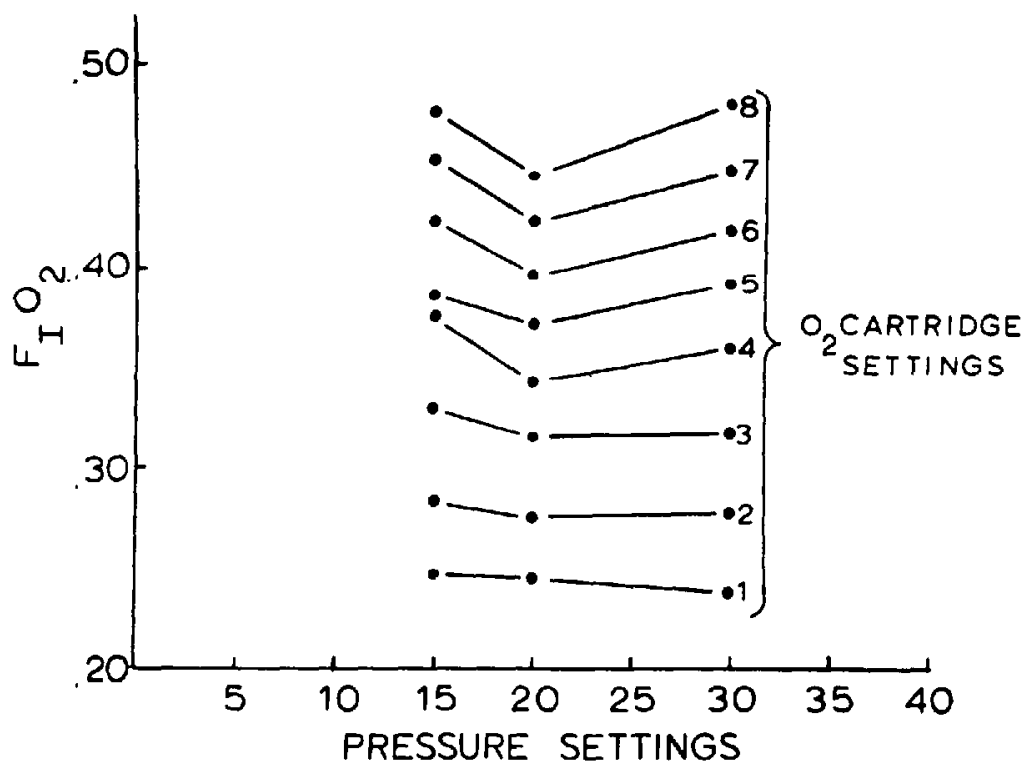

Ficure 8. F. $\mathrm{I}_{\mathrm{O}_{2}}$ values for various pressure settings and constant flow rate setting of 20 with the air-mix control pulled out. 


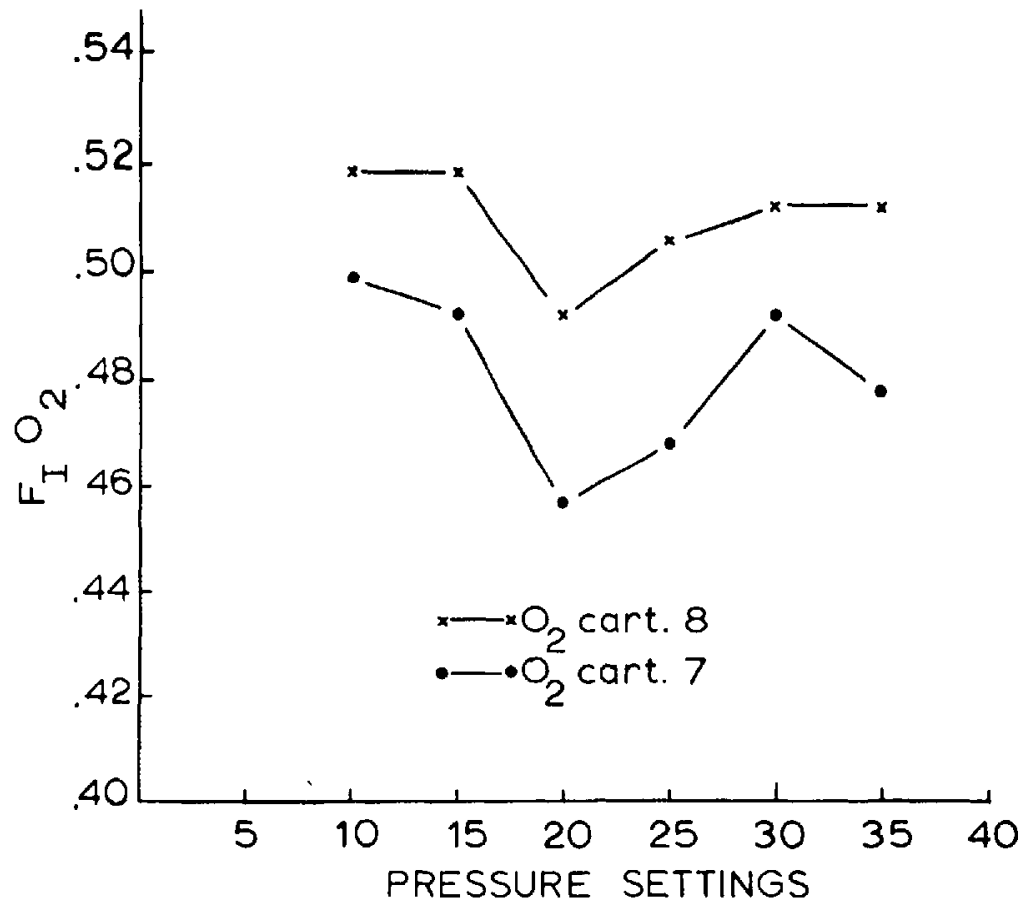

Figure 9. Effect on oxygen concentration of increasing the cycling pressure with constant minute volume and air-mix control pushed in.

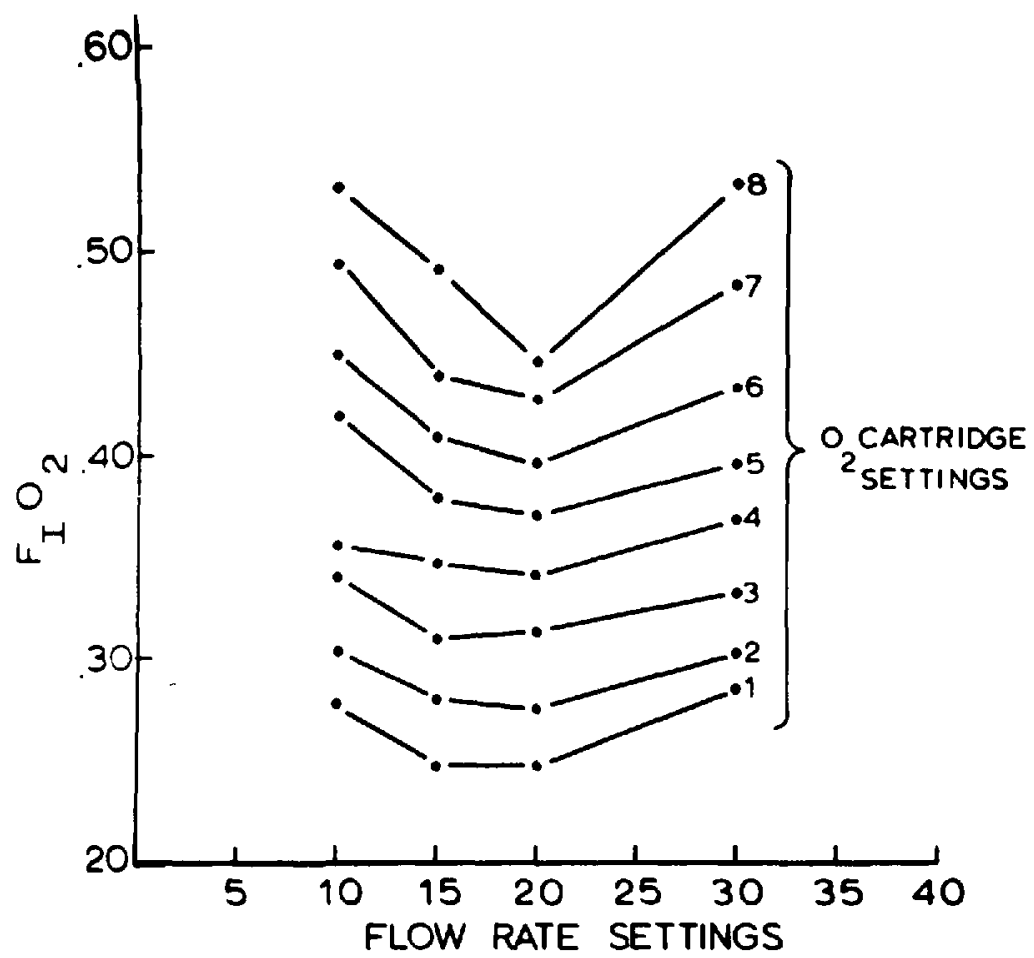

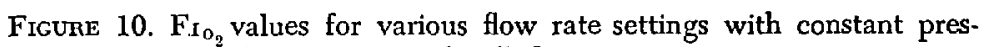
sure setting at 20 and air-mix control pulled out. 
values in the middle range of flow rate settings and varied more as the flow through the cartridge increased.

In following up and rechecking this variation caused by flow, a series of values for $\mathrm{FIo}_{2}$ was obtained from the fifth and sixth sets of conditions, and these values were recorded in Table IV. With the air-mix control pulled out and constant pressure in the lung analogue (Fig. 11), the oxygen concentration gradually fell with increase in the flow rate setting, by approximately 12 vol. per cent over the

TABLE IV

Constant Pressure $20 \mathrm{Cm}$. $\mathrm{H}_{2} \mathrm{O}$ in Lung Analogue with the Nebulizer Cartridge ON ONe full Turn

\begin{tabular}{cccccc}
\hline \multirow{2}{*}{$\begin{array}{c}\text { Flow rate } \\
\text { settings }\end{array}$} & \multicolumn{2}{c}{ Air-mix control out } & & \multicolumn{2}{c}{ Air-mix control in } \\
\cline { 2 - 3 } \cline { 5 - 6 } & $\mathrm{O}_{2}$ cart. \#7 & $\mathrm{O}_{2}$ cart. \#8 & & $\mathrm{O}_{2}$ cart. \#7 & $\mathrm{O}_{2}$ cart. \#8 \\
\hline 5 & .544 & .563 & & .491 & .533 \\
10 & .537 & .532 & & .463 & .505 \\
15 & .523 & .532 & & .463 & .498 \\
20 & .494 & .518 & & .463 & .477 \\
25 & .472 & .487 & & .463 & .477 \\
30 & .459 & .460 & .456 & .469 \\
35 & .440 & .459 & .435 & .456 \\
\hline
\end{tabular}

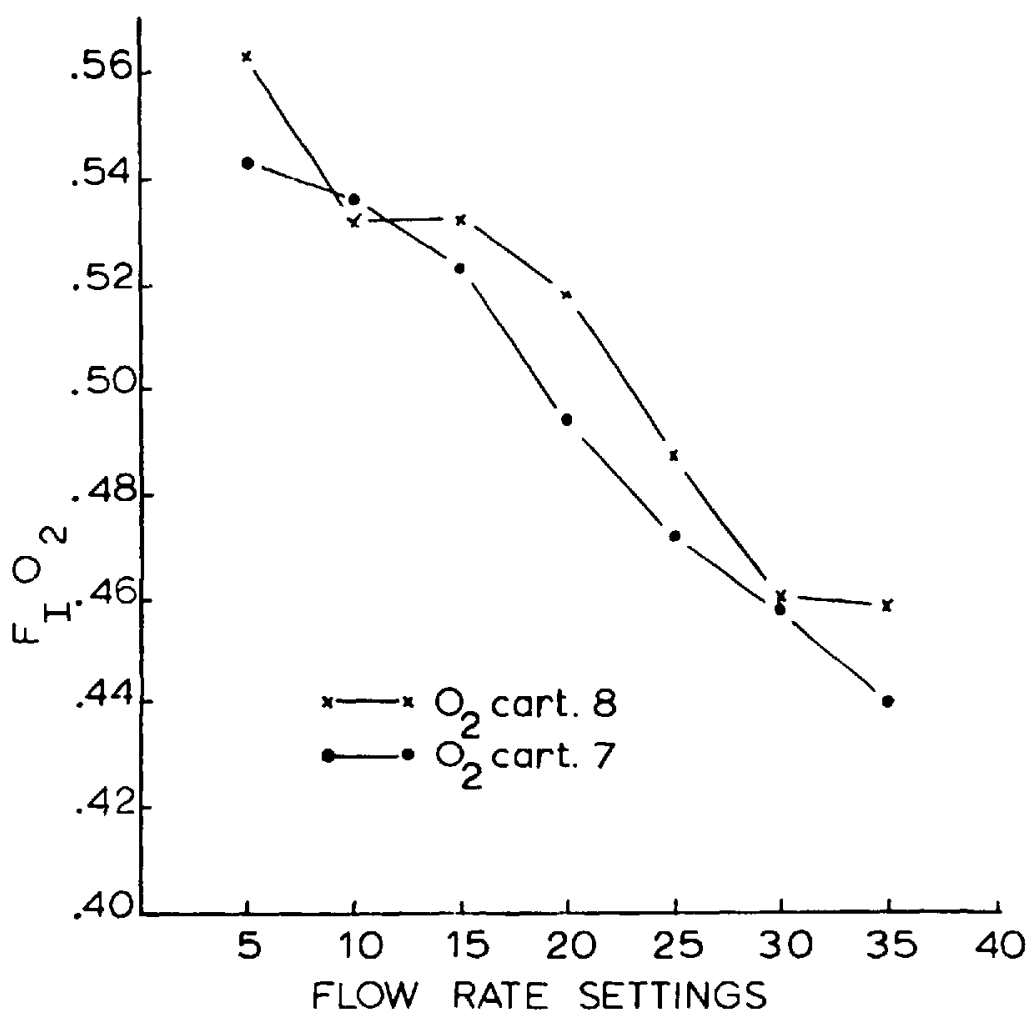

Frgure 11. Effect on oxygen concentration of increasing flow with constant pressure in lung analogue and air-mix control pulled out. 
range of settings examined. Comparison of this curve with the previous one (Fig. 10) shows a marked inconsistency in the results obtained under presumably identical conditions. However, the conditions in reality were not identical in that the actual pressure in the lung analogue was measured and maintained at a constant level to produce the findings depicted in Figure 11. With a constant pressure setting there was no appreciable variation in the oxygen concentration, but with the pressure maintained constant in the lung analogue there was a significant drop in concentration as the flow through the respirator was increased. This drop could probably be explained by the fact that at any one setting the flow through the cartridge did not change, but increased flow through the respirator added more diluent air. Also, increased flow through the respirator at constant pressure produced a shorter inspiratory phase (Fig. 12). This was observed where the pressure was maintained at $20 \mathrm{~cm} . \mathrm{H}_{2} \mathrm{O}$ in the lung analogue while the flow rate setting was varied from 10 to 35 . With a shorter inspiratory phase there was a shorter duration of oxygen inflow from the cartridge, leading to a decreased oxygen concentration.

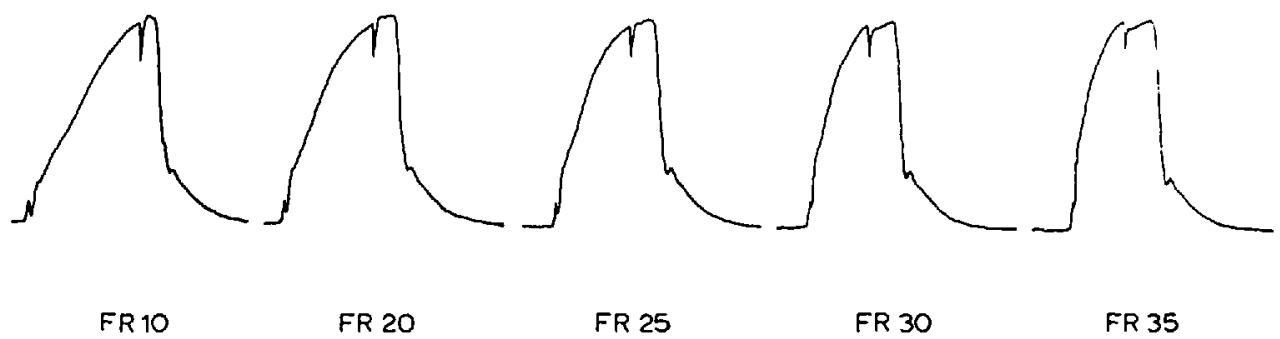

Figure 12. Pressure profiles from the lung analogue showing shortening of the inspiratory phase due to increased flow with pressure maintained constant at $20 \mathrm{~cm} . \mathrm{H}_{2} \mathrm{O}$.

The reason for the maintenance of a high oxygen concentration at the higher flow rate settings (Fig. 10) was thought to be a decrease in flow due to a fall in pressure, despite the constant pressure setting. The pressure tracings (Fig. 13) taken with the pressure setting constant at 20 showed a marked decrease in the actual pressure, measured in the lung analogue, at which the respirator cycled. The actual pressure is shown in brackets. With a drop in pressure there could be a corresponding drop in flow through the respirator without a decrease in flow through the oxygen cartridge and hence the oxygen concentration would rise.

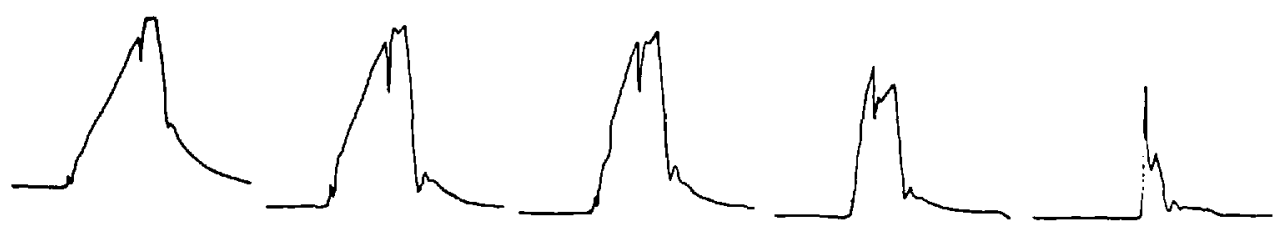

FR10 PR 20 (20) FR15 PR 20 (20) FR 20 PR 20 (20) FR 30 PR 20 (17) FR 40 PR 20 (8)

Figure 13. Pressure profles showing the drop in pressure occurring with increase in flow at a constant pressure setting of 20 . Actual pressure is shown in brackets. 
The basic change produced by the mixing cartridge on the pressure profile is shown in Figure 14. Curve $A$ is the pressure profile in the lung analogue obtained with a flow rate setting of 30 and a pressure in the lung analogue of $20 \mathrm{~cm} . \mathrm{H}_{2} \mathrm{O}$ and with both the nebulizer and oxygen portions of the cartridge turned off. The time from the onset of inspiration to the dip at the top of the curve in this case was 1.32 seconds. In curve $B$ with the nebulizer portion of the cartridge on one full turn, the duration of the inspiratory phase was shortened to 0.92 seconds. In

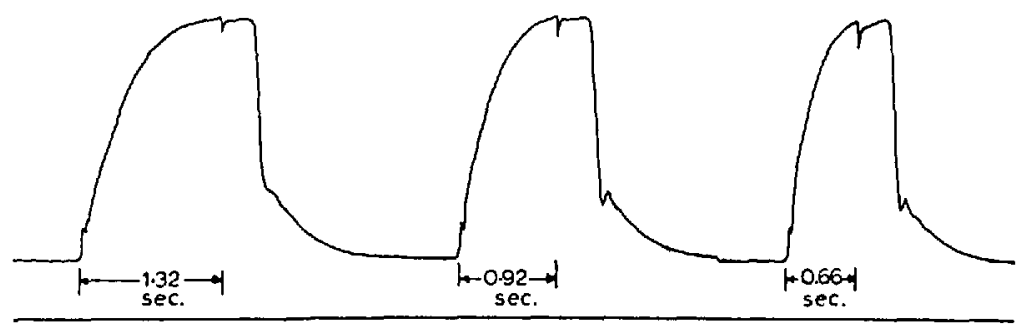

A

B

C

Figure 14. Pressure profiles from lung analogue. Flow rate 30. Pressure $20 \mathrm{~cm}$. $\mathrm{H}_{2} \mathrm{O}$. A-nebulizer and oxygen off, B-nebulizer only, C-both cartridges on.

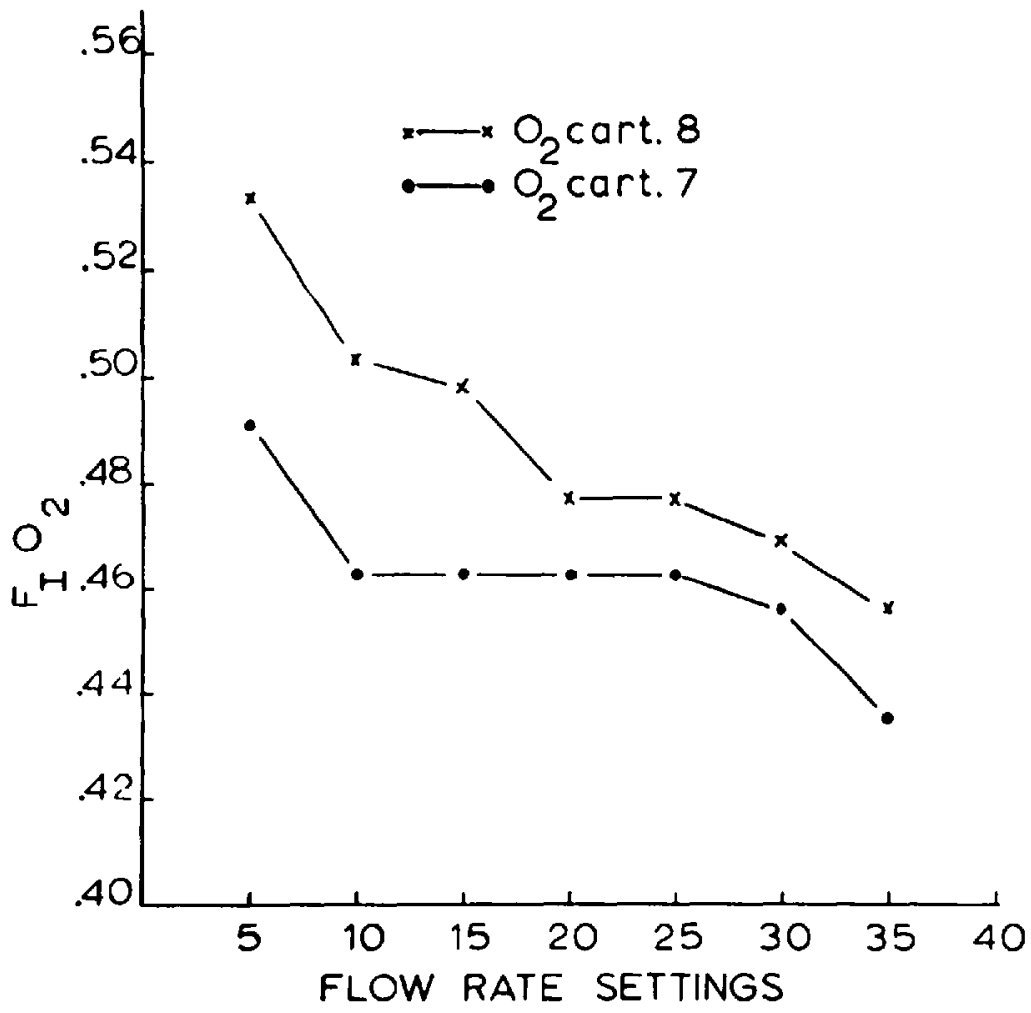

Figure 15. Effect on oxygen concentration of increasing flow with constant pressure in lung analogue with air-mix control pushed in. 
curve $\mathrm{C}$ with both the nebulizer and the oxygen portions of the cartridge on one full turn, the inspiratory time was again shortened, this time to 0.66 seconds. This shortening of the inspiratory phase was the result of more rapid triggering of the respirator due to the increased flow.

With the air-mix control pushed in (Table III and condition 6) in a situation of constant measured pressure and variable flow rate (Fig. 15), the rate and degree of the drop in oxygen concentration is less since the increase in flow for each change of the flow rate setting is not as great with the elimination of the venturi. Not only is there less increase in flow, there is also less dilution of the oxygen as a result of the lack of air entrainment.

\section{Summary and Conclusions}

Experimentation with the Bird Mark 7 respirator using the Bird Parallel Inspiratory Fow Mixing Cartridge (999 1289) to provide varying concentrations of oxygen in the inspired gas mixture was carried out. It was found that changes in the absolute pressure did not interfere significantly with the predictability of the oxygen concentrations obtained. However, the oxygen level did vary with changes in flow, being influenced more specifically by the ratio between the flow through the cartridge and the flow through the respirator; i.e., the oxygen concentration was directly proportional to the flow through the cartridge and inversely proportional to the flow through the respirator.

Though there is probably variation from one respirator to another, there appeared to be no reason why this mixing cartridge, when calibrated to one particular respirator, would not produce satisfactorily predictable oxygen concentrations within the framework of clinical usefulness.

Some recommendations might be made to the manufacturer, namely that (1) a graduated scale be provided for the oxygen metering valve, (2) the nebulizer air metering valve be fixed in one position, probably at one full turn, to prevent accidental closure and inadequate humidification, and (3) the respirator be operated on air without the venturi to obtain the best control of oxygen mixtures.

\section{RÉSUMÉ}

On a fait des expériences avec le respirateur Bird "Mark 7" en utilisant l'unité No. 9991289 (Parallel Inspiratory Flow Mixing Cartridge) pour fournir des concentrations d'oxygène variables dans le mélange de gaz inspiré. On a trouvé que les changements dans la pression absolue ne dérangent pas sensiblement les concentrations d'oxygène obtenues. Cependant, le niveau d'oxygène a varié avec les changements de débit, et ce niveau a été surtout influencé par le rapport entre le débit qui passe par l'unité 9991289 et celui qui passe par le respirateur; en d'autres termes, la concentration d'oxygène était directement proportionnelle au débit de l'unité mentionnée, et inversement proportionnelle au débit du respirateur.

Bien qu'il y ait probablement quelque différence d'un respirateur à l'autre, il 
ne semble pas y avoir de raison pour que cette unité, bien adaptée à un respirateur en particulier, ne fournisse des concentrations d'oxygène satisfaisantes dans le domaine clinique.

On pourrait faire au manufacturier certaines recommandations, à savoir : (1) qu'il y ait une échelle graduée sur la valve qui mesure l'oxygène, (2) que la valve qui mesure la vaporisation d'air soit fixée dans une position déterminée, soit à un tour complet, pour empêcher qu'elle ne se ferme accidentellement et que l'humidification soit insuffisante, et (3) que le respirateur fonctionne par l'air sans venturi pour obtenir le meilleur contrôle des mélanges d'oxygène.

\section{REFERENCES}

1. Faurley, H. B. \& Brutr, B. A. The Adequacy of Air-Mix Control in Ventilators Operated from an Oxygen Source. C.M.A.J. 90: 1394 (1964).

2. Harpuson, G. A. The High Oxygen Mixtures Delivered by the Air-Mix Control of the Bird Mark 7 Ventilator. Brit. J. Anaesth. 39: 659 (1967).

3. Seliery, G. R. \& FatrLeY, H. B. Inspired Oxygen Concentration Delivered by the Bird Ventilator. Anesthesiology. 28: 453 (1967).

4. Bird Space Technology Incorporated, Palm Springs, California, U.S.A. Catalogue 1966, Form 6966.

5. FARRLEY, H. B. \& Hunter, D. D. Mechanical Ventilators: An Assessment of Two New Machines for Use in the Operating Room. Can. Anaesth. Soc. J. 10: 364 (1963). 